\title{
Determination of thermophysical and thermokinetic characteristics of forest combustible materials
}

\author{
Alena Zhdanova ${ }^{1,}$, Svetlana Kralinova ${ }^{1}$, and Galina Nyashina $^{1}$ \\ ${ }^{1}$ National Research Tomsk Polytechnic University, 634050 Tomsk, Russia
}

\begin{abstract}
The danger of forest fires and their large-scale consequences is facing humanity more and more sharply from year to year. We carried out experimental studies to determine the thermal characteristics (thermal conductivity, heat capacity, thermal diffusivity) and thermokinetic characteristics (activation energy, pre-exponential factor) of typical forest combustible materials and their mixtures for a wide range of temperatures $(298-423 \mathrm{~K})$. A generalization of experiments for typical forest combustible materials of the Far Eastern Federal District of Russia was performed. The established experimental values can be used for mathematical modeling of occurrence, propagation and extinguishing of forest fires.
\end{abstract}

\section{Introduction}

Deterioration of the environment and air pollution are, of course, a consequence of many factors. Over the past five years, wildfires have claimed the thousands of human lives around the world [1-3]. Rare species and individual animals are dying. In addition to thousands of hectares of burnt forest massifs, numerous cases of suffocation and poisoning of people with combustion products of forest combustible materials (FCMs) should be noted.

There are four relatively independent directions forest fire-fighting: direct assessment of forest fire danger [4], prediction of the combustion front propagation [5], fire extinguishing [6], and localization of combustion source [7]. In recent years, in each of these directions, the number of theoretical studies (for example, [4-7]) is increasing. This is due to the significant progress of the scientific community in understanding the physics of the corresponding heat and mass transfer processes, phase transformations and chemical reactions. It is important to carry out experimental studies of thermophysical and thermokinetic characteristics of FCMs with the aim of forming an information database necessary for the further development of the theory of forest fires.

The purpose of this study is the experimental determination of thermophysical and thermokinetic characteristics of typical forest combustible materials of the Far Eastern Federal District.

\footnotetext{
* Corresponding author: zhdanovaao@tpu.ru
} 


\section{Experimental setup and procedure}

In this paper, the laser flash method [8] was chosen to determine the coefficients of thermal diffusivity, thermal conductivity, and specific heat of FCM under laboratory conditions. The main advantages of this method (in comparison with others) are [8, 9]: relative simplicity of measurements, high accuracy and reliability of results, applicability in a wide range of experimental conditions and materials, simultaneously measuring all basic thermophysical characteristics. In addition, the study of thermal conductivity by the laser flash method takes several times less time than the other methods [8,9].

We used the system "DLF-1200 TA Instruments". The operating principle of the system is based on the evaluation of the propagation velocity of the heat pulse in the sample. Measurements are made at temperatures in the thermostat up to $1500 \mathrm{~K}$. The error in determining the coefficients of thermal diffusivity is $\pm 2.3 \%$, the heat capacity is $\pm 4 \%$, and the thermal conductivity is $\pm 5 \%$.

We used a rotary mill "Pulverisette 14" to grind FCM. The rotor speed was 6000-20000 rpm. The average particle size was about $200 \mu \mathrm{m}$. Thus, we prepared samples of powders of the investigated materials with a mass of $0.2-0.25 \mathrm{~g}$. Using a hydraulic press, the samples were pressed into cylindrical specimens (tablets). The dimensions of the tablets corresponded to the requirements of the used measuring system, and did not exceed 12.5 $\mathrm{mm}$ in diameter and $3 \mathrm{~mm}$ in height. The density of the samples corresponded to the narrow recommended range $\left(\rho=0.71 \div 0.83 \mathrm{~g} / \mathrm{cm}^{3}\right)$. Powders were stored under ambient humidity at room temperature $\left(18-22{ }^{\circ} \mathrm{C}\right)$. We did not pre-dry the powders before experiments. To increase the degree of absorption of the laser energy and, respectively, to increase the accuracy of measurements, a layer of graphite was applied to the surface of the samples by aerosol spraying. Then the samples were placed in a thermostat using a holder and a specialized trolley (Fig. 1 a). The thermostat working volume was filled with an inert gas (nitrogen).

During the measurements, we used a calibration sample (Pyrex7740), loaded into the thermostat module simultaneously with the test materials. The values of specific heat, thermal conductivity and thermal diffusivity coefficients are determined using the software of DLF-1200 TA Instruments system. We determined mass, height, base diameter and density of each sample before placement in the thermostat. Five measurements were carried out, the results of which were averaged. The height and diameter of the tablets were measured with a micrometer. The systematic measurement error was $0.005 \mathrm{~mm}$. The mass of the samples was determined by the analytical balance Pioneer PA114. The systematic error of the measurements was $0.00005 \mathrm{~g}$. According to the Romanovskii criterion, the geometric characteristics and mass of the test tablets were evaluated. We did not reveal rough errors in the experiments. 

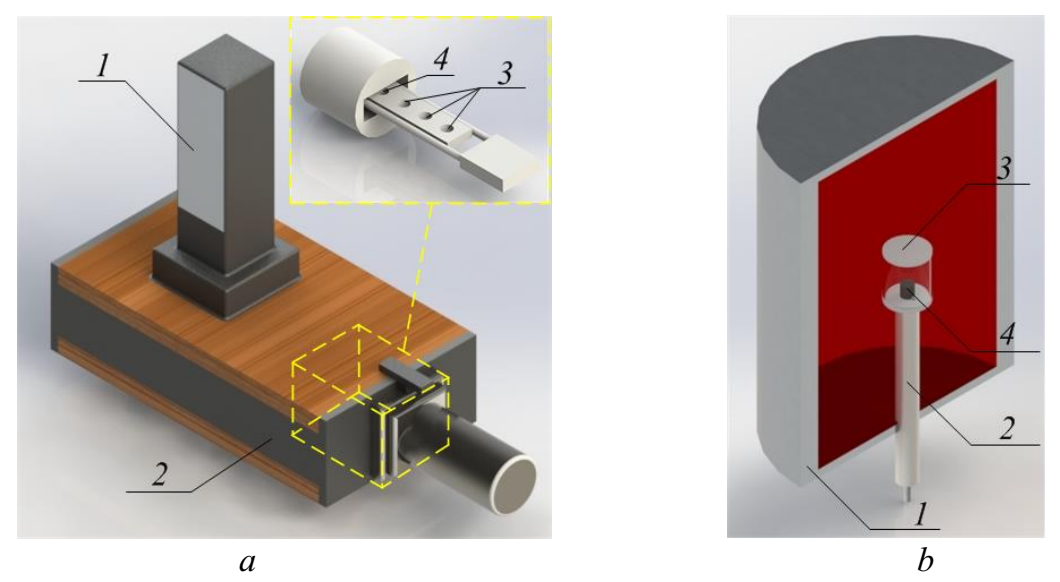

Fig. 1. Scheme of experimental setup for determining the thermophysical characteristics $(a): 1-$ laser pulse generation unit, 2 - thermostat unit, 3 - test FCM samples, 4 - calibration (reference) sample and conditional scheme of the thermo-system for thermal analysis $(b)$ : 1 - furnace, 2 - holder, $3-$ sample place; 4 - temperature sensor.

In the present work we used synchronous thermal analyzer NETZSCH STA 449F3 for experimental determination of thermokinetic characteristics of the studied materials. The device has a wider temperature range than [10] and the possibility of performing the analysis in an inert and oxidizing atmosphere. The conditional scheme of the experiment is shown in Fig. 1 b. The thermal analysis was carried out under the following conditions, corresponding to the experiments [11]: the sample mass was $25 \mathrm{mg}$; heating from $300 \mathrm{~K}$ to $1270 \mathrm{~K}$ at a rate of $10 \mathrm{~K} / \mathrm{min}$ in argon and oxygen with a gas flow rate of $100 \mathrm{ml} / \mathrm{min}$. The kinetic parameters of pyrolysis were calculated by the method [12].

\section{Results and Discussion}

Fig. 2 illustrates the established values of thermophysical characteristics of FCMs, typical for the Far Eastern Federal District, in the temperature range 298-423 K. The choice of the temperature range is due to the real conditions under which the forest leaf litter is thermally decomposed and the subsequent combustion is initiated. If we consider in general the conditions under which the forest fire begins, then in the selected temperature range, intense heating of the material and the yield of bound water occur [13]. An intensive material decomposition is realized in the temperature range $350-450 \mathrm{~K}$ [6]. It is inadvisable to carry out experiments in the temperature range up to $500-600 \mathrm{~K}$ because the acceleration of thermal decomposition processes will lead to a change in the sample density and a corresponding increase in the error of determining the thermal conductivity, heat capacity, and thermal diffusivity.

The established results (Fig. 2) contribute to the significant development of modern concepts about dependencies (type, nature, variation ranges, scale of growth) of thermophysical characteristics of typical FCMs on temperature. 

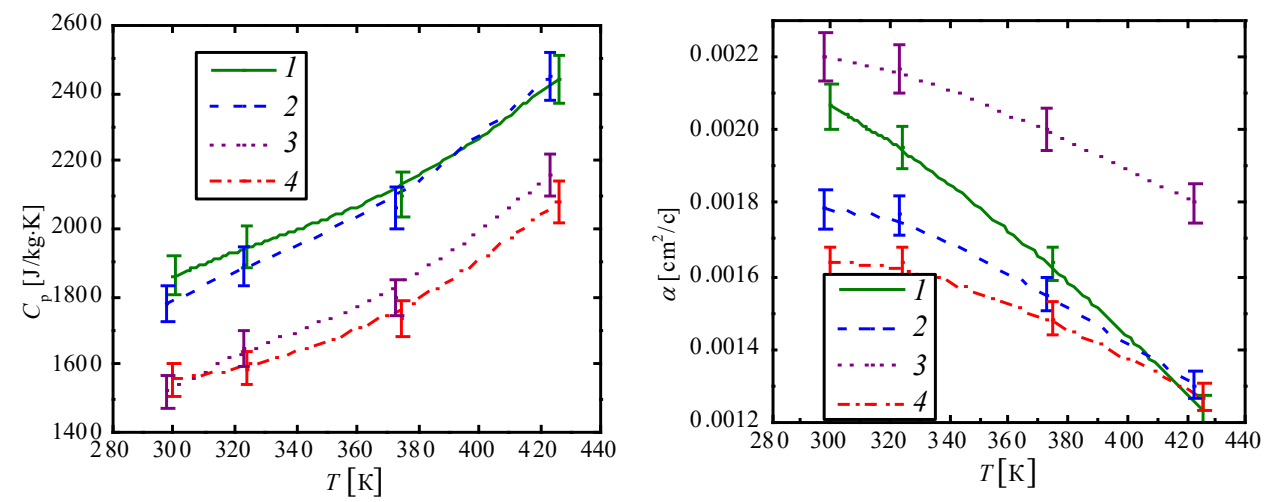

Fig. 2. The experimental values of heat capacity $(a)$ and thermal diffusivity $(b)$ of forest combustible materials: 1 - birch bark, 2 - birch branches, 3 - mixture of branches, 4 - grass.

Tables 1 and 2 show, respectively, the established thermokinetic parameters of the FCM organic mass decomposition and the formation of volatile substances in an inert and oxidizing atmosphere for all the studied boreal materials in three temperature sections.

Table 1. Thermokinetic characteristics of FCM pyrolysis in an inert atmosphere.

\begin{tabular}{|c|c|c|c|c|c|c|}
\hline FCM & $\begin{array}{c}\boldsymbol{E}, \\
\mathbf{k J} / \mathbf{m o l}\end{array}$ & $\begin{array}{c}\boldsymbol{k}, \\
\mathbf{1} / \mathbf{s}\end{array}$ & $\begin{array}{c}\boldsymbol{E}, \\
\mathbf{k J} / \mathbf{m o l}\end{array}$ & $\begin{array}{c}\boldsymbol{k}, \\
\mathbf{1} / \mathbf{s}\end{array}$ & $\begin{array}{c}\boldsymbol{E}, \\
\mathbf{k J} / \mathbf{m o l}\end{array}$ & $\begin{array}{c}\boldsymbol{k}, \mathbf{c} \\
\mathbf{1 / \mathbf { s }}\end{array}$ \\
\hline & \multicolumn{2}{|c|}{$\begin{array}{c}\text { Section 1 } \\
(430-540 \mathrm{~K})\end{array}$} & \multicolumn{2}{c|}{$\begin{array}{c}\text { Section } 2 \\
(540-630 \mathrm{~K})\end{array}$} & \multicolumn{2}{c|}{$\begin{array}{c}\text { Section 3 } \\
(630-840 \mathrm{~K})\end{array}$} \\
\hline Birch branches & 77.27 & $4.83 \cdot 10^{6}$ & 93.49 & $2.95 \cdot 10^{7}$ & 13.46 & $1.21 \cdot 10^{0}$ \\
\hline Birch bark & 139.58 & $1.86 \cdot 10^{13}$ & 93.50 & $7.27 \cdot 10^{7}$ & 14.16 & $1.09 \cdot 10^{0}$ \\
\hline $\begin{array}{c}\text { A mixture of branches (60\% } \\
\text { of spruce, 40\% of birch) }\end{array}$ & 70.34 & $1.46 \cdot 10^{6}$ & 97.82 & $9.86 \cdot 10^{7}$ & 20.57 & $4.28 \cdot 10^{0}$ \\
\hline Grass & - & - & 61.54 & $9.78 \cdot 10^{4}$ & 28.45 & $1.73 \cdot 10^{1}$ \\
\hline
\end{tabular}

The kinetic characteristics were obtained for three temperature ranges (Table 1): 430$540 \mathrm{~K}$ (first), 540-630 K (second), and 630-840 K (third). The temperature ranges were varied by no more than $10 \mathrm{~K}$ (in accordance with the error of the thermocouples) from experiment to experiment.

It was established that the thermophysical characteristics of FCMs differ significantly in different temperature ranges (Fig. 2, Tabs. 1 and 2). We can conclude that this can significantly affect the theoretically calculated times of warm-up, drying, thermal decomposition and burning out of FCMs, as well as localization and suppression of the corresponding processes.

Table 2. Thermokinetic characteristics of FCM pyrolysis in an oxidizing atmosphere (430-840 K).

\begin{tabular}{|c|c|c|}
\hline FCM & $\boldsymbol{E}, \mathbf{~ k J} / \mathbf{m o l}$ & $\boldsymbol{k}, \mathbf{1} / \mathbf{s}$ \\
\hline Birch branches & 99.93 & $2.32 \cdot 10^{7}$ \\
\hline Birch bark & 176.22 & $6.11 \cdot 10^{13}$ \\
\hline A mixture of branches (60\% of spruce, 40\% of birch) & 85.89 & $1.09 \cdot 10^{6}$ \\
\hline Grass & 70.17 & $1.08 \cdot 10^{5}$ \\
\hline
\end{tabular}




\section{Conclusion}

Temperatures close to the values corresponding to the beginning of thermal decomposition $(350-450 \mathrm{~K})$ are of greatest interest for applied calculations (for example, in problems of gasification, pyrolysis, fire extinguishing). The results of a comparative analysis of the heat capacity and thermal diffusivity of FCM mixtures and their individual components have shown that, in the first approximation, it is possible to fairly accurately determine the average (it is considered to be "effective") values of heat capacity, thermal conductivity, and thermal diffusivity of a mixture of materials by analogous parameters of individual components, taking into account their relative mass fractions in mixture.

The research was funded by the grant of the President of the Russian Federation (project MK1684.2017.8)

\section{References}

1. A. Dimitrakopoulos, C. Gogi, G. Stamatelos, I. Mitsopoulos, Pol. J. Environ. Stud. 20, $327(2011)$

2. F. X. Catry, F. C. Rego, F. Moreira, F. Bacao, 1st International Conference on Modelling, Monitoring and Management of Forest Fires 119, 213 (2008) DOI: 10.2495/FIVA080221

3. D. H. Klyde, D. J. Alvarez, P. C. Schulze, T. H. Cox, M. Dickerson, AIAA Atmospheric Flight Mechanics Conference, 97625 (2010)

4. N. V. Baranovskiy, G. V. Kuznetsov Prognoz vozniknoveniya lesnykh pozharov $i$ ikh ekologicheskikh posledstviy [Forecast of occurrence of forest fires and their ecological consequences] (Siberian Branch of the RAS, Novosibirsk, 2009)

5. M. S. Vdovenko, G. A. Dorrer, P. S. Shatalov, Computational tech. 18, 3 (2013)

6. A. O. Zhdanova, R. S. Volkov, I. S. Voytkov, K. Y. Osipov, G. V. Kuznetsov. Int. J. Heat Mass Transf. 126, 703 (2018), DOI: 10.1016/j.ijheatmasstransfer.2018.05.085

7. N. P. Kopylov, A. L. Chibisov, A. L. Dushkin, E. A. Kudryavtsev, Fire safety 4, 45 (2008)

8. W. Hohenauer, L. Vozär, High Temperatures - High Pressures 35/36, 253 (2003/2004)

9. W. J. Parker, R. J. Jenkins, C. P. Butler, G. L. Abbott, J. Appl. Phys. 32 (1968)

10. M. B. Gonchikzhapov, A. A. Paletskiy, O. P. Korobeinichev, III All-Russian Conference with International Participation "Combustion of Solid Fuels", November 13-16, 2012. Institute of Thermophysics named after. S. S. Kutateladze [in Russian]

11. P. A. Maryandyshev, A. A. Chernov, N. V. Shkayeva, V. K. Lyubov, Int. J. Exp. Educ.11-1, 71 (2013)

12. T. V. Bukharkina, N. G. Digurov, Osnovy postroyeniya kineticheskikh modeley: uchebnoye posobiye [Fundamentals of the construction of kinetic models: a textbook]. (RKHTU im. DI. Mendeleyev, Moscow, 1999)

13. A. M. Grishin, Matematicheskiye modeli lesnykh pozharov [Mathematical models of forest fires] (Izd-vo TSU, Tomsk, 1981) 